\title{
Análisis de los Estados Financieros de Southern Peru C.C. Sucursal del Perú
}

\author{
Dr. Justo FRANCO FALCÓN
}

\section{RESUMEN}

Vamos analizar los estados financieros de Southern Peru Copper Corporation, Sucursal del Perú (en adelante la empresa), correspondiente a los ejercicios terminados al 31 de diciembre de 2012 y 2011, para lo cual calcularemos las razones o índices financieros significativos que nos permita conocer su situación económica y financiera, a esas fechas.

Los índices financieros más importantes se presentan analizando los datos obtenidos de los estados financieros mencionados y son los denominados índices de liquidez, gestión, solvencia y rentabilidad. Southern Perú Copper Corporation Sucursal del Perú es una sucursal de Southern Copper Corporation (Casa Matriz) de Estados Unidos de América y Subsidiaria indirecta del Grupo México S.A. de C.V. de México. Los estados financieros de la empresa, terminados al 31 de diciembre de 2012 y 2011 fueron auditados por la sociedad de auditoría, Beltrán, Gris y Asociados A. Civil de R.L, representante en el Perú de Deloitte Touche Tohmtsu Limited. Según el informe de auditoría la actividad de la empresa comprende operaciones de minado, molienda y flotación de mineral para producir concentrados de cobre, la fundición de concentrado de cobre para producir ánodos y la refinación de los mismos para producir cátodos de cobre. La empresa también produce cobre refinado, plata, molibdeno y pequeñas cantidades de otros metales contenidos en el mineral de cobre que son tratados como subproductos. La producción de cobre es principalmente exportado a Europa, el lejano Oriente, los Estados Unidos de América y otros países de América ${ }^{1}$.

\section{ÍNDICE O RATIO DE LIQUIDEZ}

El índice de liquidez general de la empresa al 31-12-2012 fue de 2.8 (1,95 al 31-12-2011) lo que muestra que la administración mantiene suficiente efectivo

1 Informe de Auditoría de los estados financieros al 31-12-2012 y al 31-12-2011 realizados por Beltrán Gris y Asociados A. Civil de R.L. y presentado a La Superintendencia de Mercado de valores. 
y equivalente en efectivo proveniente de sus actividades de operación lo que le permite hacer frente a sus obligaciones corrientes. Las enormes cantidades de ganancias acumuladas en los años de bonanza han permitido a la empresa acumular suficiente efectivo para afrontar cómodamente el riesgo de liquidez.

\section{ÍNDICE "PRUEBA ÁCIDA"}

El índice denominado "prueba ácida" de la empresa al 31-12.2012 fue de 1,77 (1.13 al 31-12.2011).Estos índice muestran que la administración mantiene con prudencia suficiente efectivo y equivalente en efectivo que le permite hacer frente a sus obligaciones a corto plazo.

\section{ÍNDICES DE GESTIÓN}

Estos índices muestran los efectos de las decisiones y políticas seguidas por la administración en la utilización de los fondos de la empresa.

\section{ÍNDICE ROTACIÓN DE INVENTARIO}

Este índice al 31-12-2012 fue de 4.72 (5.18 al 31-12-2011) muestran que el inventario de productos terminados, en proceso, suministros, etc. son realizados y utilizados a corto plazo, debido a la gran demanda que tiene sus productos en el mercado internacional.

\section{ÍNDICE DE ROTACIÓN DEL ACTIVO FIJO}

Este índice al 31-12-2012 fue de 1.51 (1.6 al 31-12-2011), muestran que la utilización del activo fijo fue eficiente en los dos ejercicios.

\section{ÍNDICE DE ROTACIÓN DEL ACTIVO TOTAL}

Este índice al 31-12-2012 fue de 0.91 (1.12 al 31-12.2011) muestra que en el año 2012 la utilización del activo total fue menos eficiente que en el 2011 como resultado de la disminución de las ventas. En efecto en los años 2012 y 2011 las ventas ascendieron de US\$2.952317000 a US\$ 3.179626000 respectivamente, lo que significa que las ventas disminuyeron en 2012 en US \$227209,000 con respecto a 2011. Las notas a los estados financieros no señala las razones de la disminución. Pero como las estadísticas publicadas por el Banco Central de Reserva del Perú señalan que los precios de cobre (producto principal que vende la empresa) bajaron en el mercado internacional, es razonable inducir que esta fue su principal causa. 


\section{ÍNDICE DE COSTO DE VENTAS}

De acuerdo con los datos del cuadro 1, la relación del costo de ventas con las ventas al 31-12-2012 fue de $47.37 \%$ (45.84 \% al 31-12 2011), muestra la proporción de las ventas que fue absorbida por su costo. En el año 2005 dicha relación fue de $28.34 \%$, o sea mucho menor, lo que refleja que los costos de producción subieron en los años 2011 y 2012. Llama la atención que los costos hayan aumentado casi el $20 \%$ en una empresa que aplica alta tecnología en sus operaciones de producción donde se supone que la productividad debe haber aumentado en un lapso de 7 años. La información de auditoría no revela la estructura del costo de venta, a pesar de que la empresa cuenta con tres importantes centros de costos de producción minera; Toquepala situada en Tacna, Cuajone situada en Moquegua y la fundición y refinería en la ciudad de Ilo. Esa falta de transparencia no permite conocer los componentes de los costos de producción de los grandes centros de costos mencionados: la extracción y producción de concentrados para producir ánodos y la refinación para producir cátodos de cobre.

Según las notas a los estados financieros no se conoce el costo del trabajo con relación al total del costo de venta. No se conoce si la participación de los trabajadores ha aumentado como consecuencia del aumento de los ingresos por efecto de la subida de los precios de los metales en el mercado internacional. Tampoco se conoce la proporción de los trabajadores que tienen una relación laboral directa con la empresa y qué proporción de trabajadores laboran bajo contrato con empresas contratistas en las cuales no gozan de la las mismas condiciones laborales y los mismos derechos de los que laboran de manera directa para la empresa.

Cuadro $\mathrm{N}^{\circ} 1$. Estado de Resultados en miles de dólares al 31 de diciembre de 2012 y 2011

\begin{tabular}{|l|r|r|r|r|}
\hline & $31 / 12 / 2012$ & $\%$ & $31 / 12 / 2011$ & $\%$ \\
\hline Ventas netas & $2,952,317$ & 100 & $3,179,626$ & 100 \\
\hline Costo de ventas & $-1,398,170$ & 47.36 & $-1,457,465$ & 45.84 \\
\hline Ganancia bruta & $1,554,147$ & 52.64 & $1,722,161$ & 54.16 \\
\hline $\begin{array}{l}\text { Ganancia antes de impuestos a las } \\
\text { ganancias }\end{array}$ & $1,414,611$ & 47.92 & $1,536,445$ & 48.32 \\
\hline Gastos impuesto renta & $-421,006$ & 14.26 & $-458,382$ & 14.42 \\
\hline Ganancia neta & 993,605 & 33.66 & $1,078,063$ & 33.9 \\
\hline Resultado integral total & 990,049 & 33.53 & $1,154,471$ & 36.31 \\
\hline
\end{tabular}

Fuente: Estados financieros de Southern Perú C.C.

Informe de auditoría de los estados financieros efectuado por representante de Deloitte. 


\section{ÍNDICES DE SOLVENCIA}

Los índices de solvencia mide la capacidad de endeudamiento de las empresas. Estos índices indican el respaldo con que las empresas cuentan frente a sus deudas totales.

\section{ÍNDICE DE ENDEUDAMIENTO PATRIMONIAL}

Este índice relaciona las deudas totales (pasivo corriente más pasivo no corriente) con el patrimonio. Indicando la proporción de éste comprometida por las deudas, lo que da una idea de la autonomía financiera.

La relación del Pasivo Total con el Patrimonio al 31-12-2012 fue de $13.22 \%$ (18.62\% al 31-12-2011), muestra que la autonomía financiera de la empresa mejoró en el 2012 con respecto al año 2011.El incremento de la autonomía financiera fue el resultado del crecimiento del patrimonio, como consecuencia de las sobre ganancias obtenidas por la empresa.

\section{ÍNDICE DE ENDEUDAMIENTO DEL ACTIVO}

Este índice relaciona los fondos aportados por los acreedores con el activo total. Esta relación al 31-12-2012 fue de $11.67 \%$ (15.69\% al 31-12-2011). Este índice muestra otro aspecto del incremento de la autonomía de la empresa.

\section{ÍNDICES DE RENTABILIDAD}

Índice de Ganancia Bruta

Como se observa en el cuadro 1, la relación de la ganancia bruta con las ventas al 31-12-2012 fue de 52.64\% (54.16\% al 31-12-2011), habiendo sido dicha relación de $71.66 \%$ en el año 2005. La disminución de la ganancia bruta fue el resultado del aumento de los costos de ventas en los años 2011 y 2012, cuyos factores no están incluidos en el informe de auditoría.

\section{ÍNDICE DE LOS GASTOS POR IMPUESTO A LA RENTA}

La relación del impuesto a la renta con las ventas al 31-12-2012 fue de 14.26 $\%$ (14.42 \% al 31-12-2011), habiendo sido dicha relación de 18,43\% en el año 2005.La disminución del pago del impuesto a la renta refleja que la Ley No.29788, que modificó la Ley de Regalía Minera(Ley 28258),no permitió al Estado captar más impuesto, no obstante que la empresa obtuvo sobre ganancias como consecuencia de que los precios del cobre siguieron subiendo en el mercado internacional. De esa manera el Perú perdió la oportunidad de recaudar 
más impuestos para invertirla en infraestructura, educación, salud y en tantas necesidades que tiene la población.

\section{ÍNDICE DE UTILIDAD NETA}

La relación de la utilidad neta con las ventas al 31.12.2012 fue de $33.66 \%$ (33.90 \% al 31.12.2011), habiendo sido dicha relación $42.09 \%$ en el año $2005^{2}$. Es decir, una alta tasa de rentabilidad para uno de los grandes inversionistas transnacionales que opera en el Perú.

\section{ÍNDICE DE RENTABILIDAD NETA}

La utilidad neta al 31-12-2012 fue de US \$ 990,049,000, relacionada con el patrimonio de 2,394,665,000 (al 31-12-2011) da el porcentaje de $41.34 \%$, es decir una alta tasa de rentabilidad, muy superior a la rentabilidad patrimonial $13.4 \%$ de las 500 Corporaciones más grandes de los Estados Unidos de América). Fue de US \$ 1'154'471,000 relacionado con el patrimonio de US \$ 2’118'078,000 nos da 54.5\% lo que significa que en menos de 3 años la Southern Perú C.C recuperó su patrimonio ${ }^{3}$.

\section{BIBLIOGRAFÍA}

1. CERENS Escuela de Gestión y Economía, publicado por La Primera, 28/08/2013.

2. Comisión Nacional Supervisora de Empresas y Valores, indicadores financieros empresariales 1984.

3. Deloitte T.T.L, informe de auditoría de los estados financieros al 31-12-2012 y al 31-12-2011, presentados por la empresa al S.M.V.

4. Deloitte T.T.L, informe de auditoría de los estados financieros al 31-12-2005 presentados por la empresa al S.M.V.

5. Www.smv.gob.pe//frm

2 Informe de Auditoría de los Estados Financieros al 31-12-2005, presentado por la empresa a la Bolsa de Valores de Lima.

3 GERENS publicado por La Primera 28-08-2013 Si consideramos la utilidad neta al 31-12-2001 